\title{
An Hypothesis for the Pathogenesis and Treatment of
} Recurrent Peptic Ulcers

The Zollinger-Ellison triad - gastric hypersecretion, recurrent peptic ulcer and non-ß-cellular pancreatic insuloma - is a well known syndrome and a generally accepted clinical entity. More than one hundred cases have been reported in the U.S.A. and elsewhere.

Since the first reports on the Zollinger-Ellison syndrome [1], we never omitted a careful examination of the pancreas during any gastric operation, whether for ulcer or not, but not a case of insuloma has been discovered in more than 3000 consecutive gastrectomies although several re-resections were performed for recurrent ulcers, often of severe or atypical localization, viz. in cases where an islet-cell adenoma could be suspected.

It was on these very occasions that we noticed the existence of pancreatic lesions of nonneoplastic but inflammatory type in those patients whose symptomatology and history were probatory for a Zollinger-Ellison case. Needless to say, we do not refer to pancreatic alterations near a penetrating ulcer and dependent on the ulcer. We always found an enlarged pancreas, of increased consistency, especially in the body and the tail, in multinodular form, rarely with some Editorial

333

swelling of the capsule. Biopsy specimens taken in any case of this type failed to demonstrate the existence of neoplastic lesions, even of an adenomatous type. Clear signs of hypertrophy, hyperplasy and inflammatory changes were, on the contrary, always present.

These alterations were found by us at the second or third operation for peptic ulcers, but they were always already present at the first one, at least in those patients of whose operatory findings we were certain.

As every research for an islet-cell adenoma had been unsuccessfull, and many inflammatory changes had been observed instead, we thought it possible that not only nesidioblastomata could be responsible for a recurrent ulcer but also cronic and subacute types of pancreatitis. Some cases were reported by one of us in 1959 [2]. Although glucagon could be the intermediate pathogenetic factor, in this case also, as Ellison suggested for nesidioblastomata, many clinical and experimental facts seem to demonstrate for the HGF and inhibitory action on gastric secretion.

Moreover, we cannot overlook other substances related to pancreatic function such as vagotonin, pancreozymin, callicrein and trypsin. Our observations which seemed to suggest an inflammatory pancreatic participation in the pathogenesis of recurrent peptic ulcer persuaded us that a therapy with a callicrein-trypsin inhibitor could prove useful and we therefore assayed in these patients the effect of trasylol, a pancreatic purified extract, that Asang and others [3-6] had successfully used in acute pancreatitis treatment.

Though our experience is obviously limited, therapeutic results were consistently good. Trasylol was administred at a does of 8-10,000 u. a day, divided in two or three i.v. injections. After a 48 hour treatment, in one case after the first introduction of $2000 \mathrm{u}$. by drop perfusion, 
epigastric pain disappeared, general conditions seemed to improve, appetite and digestion returned to normal.

$\mathrm{X}$-rays pictures taken at seven day intervals demonstrated a progressive reduction of the ulcerous plus.

All the patients treated were dismissed after a period of 30-40 days without any operation and, as far as we know, they are doing well since then. In one patient, this therapy made a fourth operation for a stomal ulcer unnecessary after: (a) Polya gastric resection; (b) de-gastrogastroresection; (c) degastro-gastroresection and vagotomy.

334

\section{Editorial}

The first symptoms of the stomal ulcer had begun 25 days after the third operation.

How can we explain these favorable results? It is certain that the improved pancreatic function had its direct action on the gastric function and indirectly on the ulcerative lesion. As pancreatitis itself probably plays a great part in the symptomatology, the subsiding of the inflammatory lesions, justifies the change in the symptoms. But the dramatic effect of trasylol on the ulcer itself shown by the X-ray controls and the interruption of the tragic chain of recurrences, seem to demonstrate a direct effect on an ulcerogenic factor which can only be related to the inhibition of trypsin and callicrein. Leger [7] in 1952 had found that in cronic pancreatitis blood levels of active trypsin rise proportionately with the importance of the inflammatory process in the pancreas.

This type of mechanism could support the theory of the great importance that the pancreas could have in the pathogenesis of peptic ulcer and it again suggests the hypothesis that not only insular adenomata can take part in the pathogenesis but also inflammatory lesions.

Communication to the «Société de Chirurgie de la Méditerranée Latine», Nice (France), 7-8-9 may 1961.

References

Zollínger, R. M. and Ellison, E. H.: Pancreatic endocrine function and peptic ulceration. Ann. Surg. 142: 709 (1955).

Marconi, R. and Cravero, D.: Sul importanza del fattore pancreatico nella reci-diva precoce dell'ulcera peptica. Min. med. 51: 1501 (1960).

Asang, E.: Wandlungen in der Therapie entzündlicher Erkrankungen der Bauch-speicheldrüse. Dtsch. Z. Chir. 293: 645 (1960).

Bedacht, R.: Behandlung akuter und chronischer Bauchspeicheldrüsen-Erkran-kungen. Ärzt. Praxis 10: Nr. 50 (1958).

Bedacht, R.: Pankreatitis-Behandlung mit einem Kallikrein-Inaktivator. Ärzt. Forsch. 12: 371 (1958).

Kyrle, P.: Die akute Pankreatitis, Diagnose und Therapie. Wiener klin. Wschr. 72: 170 (1960). Leger, L.: Exploration radio-chirurgicale du pancreas. J. Chir. Paris 68: 518 (1952).

P. C. Borsottí and R. Marconi

From the Surgical Department C, Ospedale San Giovanni, Turin, Italy (Head: Prof. P. C. Borsotti). 